\title{
Practice-changing publications: Male infertility
}

\author{
Jesse Ory, MD, FRCSC
}

Department of Urology, Dalhousie University, Halifax NS, Canada

Cite as: Ory J. Practice-changing publications: Male infertility. Can Urol Assoc J 2022;16(2):13-4. http://dx.doi.org/10.5489/cuaj.7734

The CUA has introduced a webinar series called PracticeChanging Publications (PCP series), which features Canadian experts discussing recent data that have impacted their field. CUAJ is proud to present summaries of these talks and the important research discussed in this series.

If you missed any of the webinars, you can access them at https://www.cua.org/UROpedia and earn all-important CPD Section 3 credits!

\section{Introduction}

This article highlights three practice-changing publications in male infertility that have come out in the last year. These publications shed new light on testosterone therapy and its impact on fertility, the effects of the COVID-19 vaccine on semen parameters, and the need for discussion of fertility preservation in individuals with cancer.

\section{Testosterone therapy and infertility}

Historically, testosterone therapy (TT) has been anathema to male fertility. ${ }^{1}$ Using exogenous TT suppresses the hypothalamic-pituitary-gonadal axis and suppresses intratesticular testosterone, resulting in azoospermia in the majority of men. ${ }^{2}$ This is thought to occur due to disruption of the pulsatile release of gonadotropins and eventual suppression of luteinizing hormone (LH). ${ }^{3}$

Natesto is a newly developed, short-acting nasal testosterone given two or three times daily. It became available in Canada in 2016. ${ }^{4}$ The short-acting properties of the intranasal testosterone mimic physiological testosterone release, leading to a hypothesis that it may preserve spermatogenesis by maintaining release of gonadotropins. Ramasamy et al recruited 60 reproductive-aged men with hypogonadism, of whom 33 finished six months of followup while on Natesto. ${ }^{5}$ Thirty of 33 had serum testosterone reach eugonadal levels, and $\mathrm{LH}$ and follicle-stimulating hormone (FSH) decreased a small but statistically significant amount. Regarding semen parameters, one man became azoospermic and three became severely oligospermic during the trial. On average, however, there was no statistically significant decrease in total motile sperm count or semen concentration at six months. ${ }^{5}$

Any man of reproductive age about to start TT should be made aware of the impacts of TT on fertility. In men who wish to preserve sperm count, intranasal testosterone is now an option that can be considered. It is important to follow sperm count and gonadotropin levels in these men, in the rare chance that their sperm counts drop.

\section{Male fertility and COVID-19 vaccine}

As of writing this, $75.04 \%$ of the total Canadian population are fully vaccinated for COVID-19. ${ }^{6}$ Certain experts have recommended that up to $80 \%$ of eligible adults need to be fully vaccinated to prevent spread, with some groups advocating for even higher vaccine coverage in light of recent variants. ${ }^{7}$ When broken down by age group, adults of reproductive age have the lowest rate of vaccine uptake in Canada. ${ }^{6}$ Recent reports show that fear regarding side effects, in particular regarding fertility implications, are driving these concerns..$^{8,9}$ This is fueled, in part, by high-profile individuals raising unfounded fears regarding the vaccine's safety with respect to fertility. ${ }^{10}$ Our group in Miami published the first prospective study on the effects of the COVID-19 vaccine on sperm parameters. ${ }^{11}$ Forty-five men were recruited to provide a semen sample prior to their first dose of an mRNA vaccine, and again 70 days after their second dose. We did not find any significant decrease in semen volume, concentration, total motile sperm count, or motility after both doses of either mRNA vaccine. Since this was published, our results have been replicated by groups in Israel, and data on female fertility has emerged that is reassuring as well. ${ }^{12}$ Hopefully, these data can instill confidence in young individuals that it is safe to proceed with COVID vaccination.

\section{Fertility preservation awareness}

As therapeutics for cancer advance, long-term survival of individuals with cancer improves. With this, an increased focus on survivorship - living through and beyond cancer — is taking place. ${ }^{13}$ The impact of cancer and its treatments on fertility is a major survivorship issue that is often not 
addressed with patients. Having cancer, and undergoing treatment for it, can temporarily or permanently impact fertility potential, and can leave individuals infertile. ${ }^{14}$ If they and their care providers are aware of this, the ability to have a family can be maintained through fertility preservation. One of the biggest barriers to this is simply raising awareness among patients. Patel et al surveyed patients with cancer undergoing chemotherapy at tertiary oncology centers in the U.S. ${ }^{15}$ They found that overall, only $43.5 \%$ of individuals were informed of the impacts of chemotherapy on fertility. Even in individuals in their early 20 s, up to $28 \%$ were not informed. Failing to discuss fertility with patients with cancer can have serious negative effects on survivorship. Because of this, the American Society of Clinical Oncology has recommended discussing fertility as early as possible in anyone diagnosed with cancer. ${ }^{16}$ Decisional regret can be a major burden for patients, with resulting infertility being a significant source of grief and decreased quality of life. ${ }^{17}$

Awareness of this problem is important, as care providers need to discuss fertility with cancer patients as early as possible in their diagnostic and therapeutic pathway.

\section{Conclusions}

Much is changing in infertility, with new therapeutics and new avenues for patient advocacy coming to light in recent years.

Competing interests: The author does not report any competing personal or financial interests related to this work.

\section{References}

1. Crosnoe LE, Grober E, Ohl D, et al. Exogenous testosterone: A preventable cause of male infertility. Transl Androl Urol 2013;2:106-13.

2. Patel AS, Leong JY, Ramos $L$, et al. Testosterone is a contraceptive and should not be used in men who desire fertility. World J Mens Health 2019;37:45-54. https://doi.org/10.5534/wimh.180036
3. Anderson RA, Baird DT. Male contraception. Endocr Rev 2002;23:735-62. https://doi.org/10.1210/ er.2002-0002

4. Rogol AD, Tkachenko N, Bryson N. Natesto ${ }^{\mathrm{TM}}$, a novel testosterone nasal gel, normalizes androgen levels in hypogonadal men. Andrology 2016;4:46-54. https://doi.org/10.1111/andr.12137

5. Ramasamy R, Masterson TA, Best JC, et al. Effect of Natesto on reproductive hormones, semen parameters, and hypogonadal symptoms: A single-center, open-label, single-arm trial. J Urol 2020;204:557-63. https://doi.org/10.1097/JU.0000000000001078

6. Public Health Agency of Canada: Canadian COVID-19 vaccination coverage report. Ott. Public Health Agency Can. 2021. Available at: https://health-infobase.canada.ca/covid-19/vaccination-coverage/. Accessed Nov. 20, 2021.

7. Bartsch SM, O'Shea KJ, Ferguson MC, et al. Vaccine efficacy needed for a COVID-19 coronavirus vaccine to prevent or stop an epidemic as the sole intervention. Am J Prev Med 2020;59:493-503. https://doi.org/10.1016/i.amepre.2020.06.011

8. Diaz P, Reddy P, Ramasahayam R, et al. COVID-19 vaccine hesitancy linked to increased internet search queries for side effects on fertility potential in the initial rollout phase following Emergency Use Authorization. Andrologia 2021;53:e14156. https://doi.org/10.1111/and.14156

9. Berry SD, Johnson KS, Myles L, et al. Lessons learned from frontline skilled nursing facility staff regarding COVID-19 vaccine hesitancy. J Am Geriatr Soc 2021;69:1140-6. https://doi.org/10.1111/igs.17136

10. Kornfield M. Aaron Rodgers said he did the research on COVID vaccines. Here's how he was wrong, according to experts. Wash Post. Available at: https://www.washingtonpost.com/sports/2021/11/05/ aaron-rodgers-fact-check/. Accessed Nov. 20, 2021.

11. Gonzalez DC, Nassau DE, Khodamoradi K, et al. Sperm parameters before and after COVID-19 mRNA vaccination. JAMA 2021;326:273-4. https://doi.org/10.1001/jama.2021.9976

12. Chen F, Zhu S, Dai Z, et al. Effects of COVID-19 and mRNA vaccines on human fertility. Hum Reprod 2021. Available at: https://doi.org/10.1093/humrep/deab238. Accessed Nov. 20, 2021.

13. Miller KD, Siegel RL, Lin CC, et al. Cancer treatment and survivorship statistics, 2016. CA Cancer I Clin 2016;66:271-89. https://doi.org/10.3322/caac.21349

14. Wasilewski-Masker K, Seidel KD, Leisenring W, et al. Male infertility in long-term survivors of pediatric cancer: A report from the childhood cancer survivor study. J Cancer Surviv Res Pract 2014;8:437-47. https://doi.org/10.1007/s11764-014-0354-6

15. Patel P, Kohn TP, Cohen J, et al. Evaluation of reported fertility preservation counseling before chemotherapy using the Quality Oncology Practice Initiative survey. JAMA Netw Open 2020;3:e2010806. https://doi.org/10.1001/jamanetworkopen.2020.10806

16. Oktay K, Harvey BE, Partridge AH, et al. Fertility preservation in patients with cancer: ASCO clinical practice guideline update. J Clin Oncol 2018;36:1994-2001. https://doi.org/10.1200/JC0.2018.78.1914

17. Loscalzo MJ, Clark KL. (2007) The Psychosocial Context of Cancer-Related Infertility. In: Woodruff T.K., Snyder K.A. (eds) Oncofertility Fertility Preservation for Cancer Survivors. Cancer Treatment and Research, vol 138. Springer, Boston, MA. https://doi.org/10.1007/978-0-387-72293-1_13

Correspondence: Dr. Jesse Ory, Department of Urology, Dalhousie University, Halifax NS, Canada; Jesse.ory@dal.ca 